Article

\title{
Spatio-Temporal Patterns and Policy Implications of Urban Land Expansion in Metropolitan Areas: A Case Study of Wuhan Urban Agglomeration, Central China
}

\author{
Shasha Lu ${ }^{1{ }^{1} *}$, Xingliang Guan ${ }^{2}$, Chao $\mathrm{He}^{1}$ and Jiali Zhang ${ }^{2}$ \\ 1 School of Economics and Management, Beijing Forestry University, Beijing 100083, China; \\ E-Mail: hechao@bjfu.edu.cn \\ 2 National Academy for Mayors of China, Beijing 100029, China; \\ E-Mails: guanxingliang@126.com (X.G.); jialla@126.com (J.Z.) \\ * Author to whom correspondence should be addressed; E-Mail: lushasha@bjfu.edu.cn; \\ Tel.: +86-10-62-337-196; Fax: +86-10-64-928-482.
}

Received: 17 February 2014; in revised form: 24 June 2014 / Accepted: 14 July 2014 /

Published: 25 July 2014

\begin{abstract}
Relatively little attention has been paid to examining the spatial expansion features of cities at various tiers at the regional level in China, especially those located in central and western regions of the country. Based on Landsat satellite imagery from four years - 1980, 1990, 2000, and 2010, this paper investigates the spatio-temporal pattern of urban land expansion and its influencing factors in the Wuhan Urban Agglomeration (WUA) in central China. The research found that the total area of urban land expanded from $203.66 \mathrm{~km}^{2}$ in 1980 to $1370.07 \mathrm{~km}^{2}$ in 2010 , and that urban land areas increased by $423.82,167.42$, and $574.93 \mathrm{~km}^{2}$ in the periods 1980-1990, 1990-2000, and 2000-2010 respectively, exhibiting significant fluctuation between the different periods studied. Geographically, this spatial expansion pattern was characterised by conspicuous concentrations and regional imbalances across the overall study period. Whilst these spatio-temporal differences were found to be closely related to industrialisation, urban population growth, land-use policies, urbanisation guidelines (governmental plans and regulations addressing urbanisation), and national development strategy, the dominant mechanisms driving those differences varied over time. In response, the paper presents an urban-rural and regional integration strategy, with the aim of avoiding economic gaps and the inefficient utilisation of various resources in the urban agglomeration areas.
\end{abstract}


Keywords: urban land; spatio-temporal pattern; driving forces; policy implications; Wuhan urban agglomeration

\section{Introduction}

China has experienced rapid rural-urban transformation since the economic reforms and "open-door policy" initiated in 1978 [1,2]. The emergence of urban agglomerations undoubtedly represents a manifestation of China's entry into an important strategic period of urban transformation development. Although urban agglomerations can as a whole be described as occupying an incipient phase at present, they have become the most dynamic regions in the economic development pattern of China, due to their accelerated industrialisation, urbanisation, and their globalisation in relation to world economies [3]. Processes of urban agglomeration can be expected to dominate the economic development and urbanisation orientations of China [4-6]. In fact, statistical data shows that the share of China's total land area, urban population, gross domestic product, foreign direct investment, and energy consumption that is currently concentrated in urban agglomerations is $21.1 \%, 51.4 \%, 78.8 \%$, 98.1\%, and 70.4\%, respectively [7]. In another 20-30 years, urban agglomerations in China will account for as much as $60 \%$ of the nation's population, $70 \%$ of its investment and $80 \%$ of the national economy. Unfortunately, however, factors associated with the rapid growth of urban agglomerations - for instance, related socio-economic transformations, the expansion of built-up areas, the high-density concentration of population, and high-intensity interactions between these "hot regions"-have resulted in tremendous land-use morphology change, the high-risk spread of space, inefficient use of various resources, and a number of other issues [8]. It is therefore of great significance that research be undertaken which is able to accurately acquire information about the spatial expansion of urban land in relation to urban agglomerations, and thus reveal the factors and dynamic mechanisms of spatial expansion.

Previously, many papers have analysed the spatial patterns and dynamic mechanisms of urban land expansion in some "hot cities" in China, such as Beijing [9], Guangzhou [10], and Wuxi [11]. Recently, as regional urbanisation and economic integration accelerate, the spatio-temporal pattern of urban land expansion in metropolitan areas as well as the driving forces behind such expansion have become important research focuses for regional economic science, land-use science, and research in relation to the Global Land Project (GLP). For instance, the Yangtze River Delta region [12], the Pearl River Delta region [13], Beijing-Tianjin-Hebei region [14], and Sothern Jiangsu province [15], etc., have attracted the special attention of many scholars at both home and abroad. However, less attention has been attached to metropolitan areas located in central and western China. In fact, guided by the "Western Development Strategy" and the "Central Region Grow-Up Strategy", a large number of urban agglomerations in these regions have emerged and flourished. Performing roles as regional economic growth poles, the socio-economic development and urban land expansion of these urban agglomerations evidences an astonishingly rapid transformation.

It is therefore necessary to investigate the spatio-temporal patterns of urban expansion and its driving forces in central and western regions. The major objective of this paper is to examine the spatial expansion features in Wuhan Urban Agglomeration (WUA). The paper may help us know the 
spatio-temporal information of urban land expansion, its influencing factors as well as the problems appearing in the metropolitan areas located in central China during the rapid transformation development. It also might serve as a scientific decision-making reference for understanding the effect of the "Central Region Grow-Up Strategy" and in guiding cooperative spatial resource utilisation, economic integration, and socio-economic sustainable development in the Wuhan urban agglomeration. Firstly, we address urban land area information from four years (1980, 1990, 2000 and 2010), based on Landsat imagery data through the application of remote sensing and GIS technology. Furthermore, adopting the urban expansion intensity index (UEII), urban expansion differentiation index $(U E D I)$, and fractal correlation dimension $\left(D_{c}\right)$, the paper analyses the spatio-temporal pattern of the urban expansion of the Wuhan urban agglomeration, the expansion process at work, and the factors influencing that process. Finally, we present an urban-rural and regional integration strategy which might be helpful in avoiding economic gaps and the inefficient utilisation of various resources in the urban agglomeration areas.

\section{Materials and Methods}

\subsection{Study Area}

The Wuhan urban agglomeration (WUA) consists of Wuhan (the capital of Hubei Province and one of the major industrial centres in central China) and other eight cities in a $100 \mathrm{~km}$ radius from Wuhan-Huangshi, Ezhou, Xiaogan, Huanggang, Xianning, Xiantao, Qianjiang, and Tianmen (Figure 1). The agglomeration is situated within the middle reaches of the Yangtze (Changjiang) River; the longitude and latitude of its position range from $112^{\circ} 30^{\prime} \mathrm{E}$ to $116^{\circ} 10^{\prime} \mathrm{E}$, and from $29^{\circ} 05^{\prime} \mathrm{N}$ to $31^{\circ} 50^{\prime} \mathrm{N}$, respectively. The area is characterised by a humid, subtropical monsoon climate, with distinct seasons, rich soils for crops, sufficient sunshine, and abundant rainfall, all of which make the WUA region an important grain production and agricultural-product processing base in China [16]. The Wuhan urban agglomeration plays an extremely important role in the national strategic fulcrum, and is the primary dynamic growth pole in the development of central China.

Figure 1. The study area.

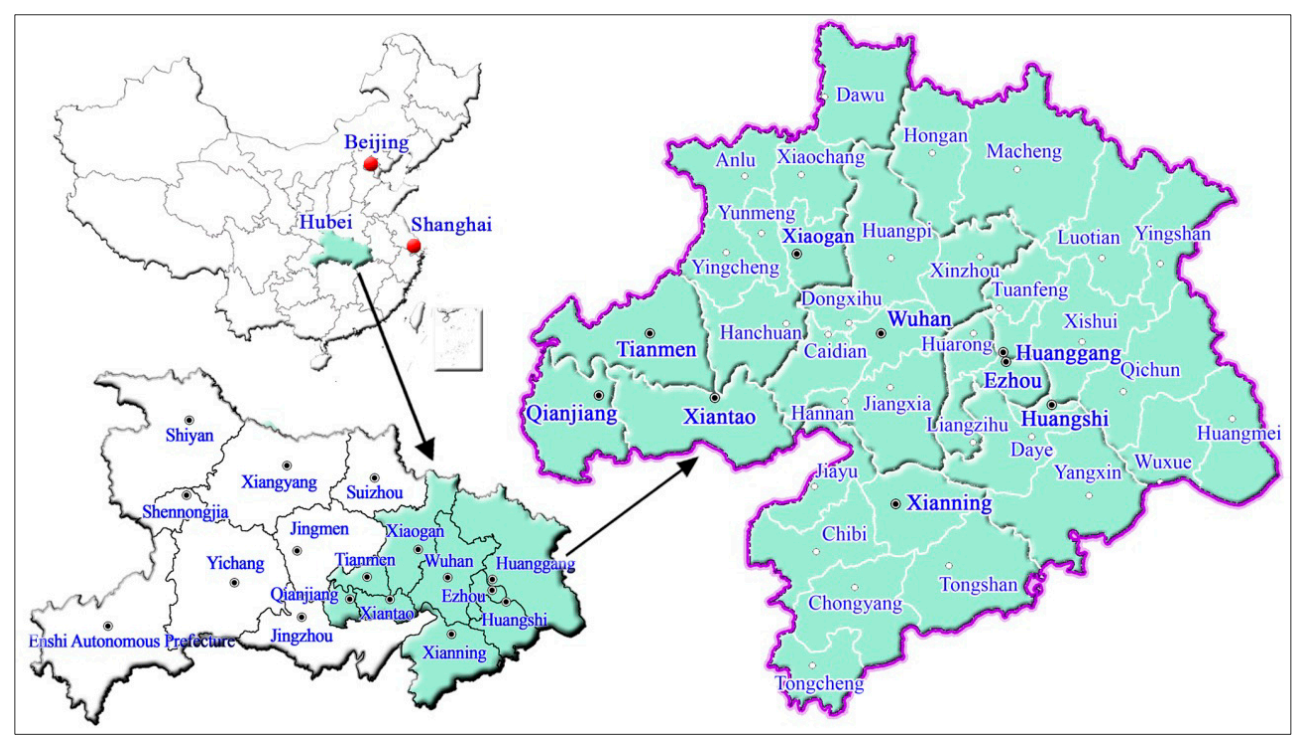




\subsection{Data Sources and Processing}

\subsubsection{Definition of Urban Area}

In general, "urban area" includes all the land use types that serve the urban function [15]. However, the delineation of "urban area" might be sensitive to the users and interpretation methods because of lack of any threshold, distance or population criteria, which would be a problem for comparing different study areas or updating existing databases by different operators over time. Considering that the paper tried to launch a macro-scale study on urban footprints in an urban agglomeration area, we defined urban area according to the following criteria with reference to [15]: (a) if the open space, including water bodies and green lands, is completely surrounded by other urban land use types (e.g., residential, industrial and commercial etc.), it is designated as an urban area and deemed contained within the urban boundary; (b) if an industry development zone or economic and technical development zone is very close to a city or town, its boundary is merged into the urban boundary.

\subsubsection{Satellite Image Processing}

Satellite images are often used to analyse land use change [17,18]. We collected seven views covering the WUA region from Landsat TM/ETM+/MSS satellite images of four years (i.e., 1980, 1990, 2000, and 2010). These satellite images can be easily downloaded from the United States Geological Survey (USGS). In order to extract the urban land more clearly, the predominant cloud-free images of the study area were acquired on 16 October 1979 (MSS), 12 October 1991 (TM), 26 February 2001 (TM) and 10 December 2011 (ETM+), respectively. Seven scene images of the four years all are in the dry season (October to February).

Early in the mid-1990s, supported by a key project entitled "Remote Sensing Investigation and Dynamic Study on Resources and Environment in China”, Chinese Academy of Sciences (CAS) established the land-use/cover change (LUCC) database, which produces thematic maps at a scale of 1:100,000. These LUCC data were obtained through visual interpretation and digitisation of satellite remote sensing data provided by the US Landsat TM/ETM images which have a spatial resolution of 30 by 30 meters [6]. At present, the databases contain LUCC datasets for four different years (1980s, 1995, 2000, and 2005). The original thematic maps consist of seven first class land-use types, i.e., cropland, forest, grassland, residential area and land for standalone industrial and mining sites, water region, and unused land, and 27 subclasses [14]. In this paper, we obtained the urban land information for the four years through the post-classification image comparison method [19]. The main steps are as follows: (i) Process remote sensing images (including repairing the image strip of Landsat ETM+ images based on multi-image local adaptive regression analysis model (MLARAM), optimising multi-band combination of the images, geometrical correction using a polynomial method, and enhancing texture characteristics); (ii) Extract land parcels related to urban built-up area (one of the subclasses and coded as 51) from the LUCC vector data of the year 2000; (iii) Overlay the layer of land parcels with the Landsat images of 2000; (iv) Adjust and correct the land parcels based on the images according to our definition of urban land; (v) Overlay the adjusted urban land information of 2000 with the Landsat images of 1980, 1990 and 2010; (vi) Obtain the urban land information for the years 1980, 1990, and 2010 using the post-classification image comparison method [20]. This method 
compares two or more separately classified images at different dates. Prior classification has to be carried out before making the comparison. Different epochs of Landsat satellite images are employed to interpret the dynamic change of vector data. If land cover changes are detected, it would be labelled a new symbol, or it would be labelled the same as before. In our study, the vector data in 2000 was the prior classification and viewed as ancillary data in the process. Landsat satellite images in 1980, 1990, 2010 and the vector data in 2000 were employed together to interpret the dynamic urban land change. Through these ways mentioned above, we obtained the urban land data for the study years.

\subsubsection{Accuracy Analysis}

During the process of interpretation of TM images and land-cover classifications, Chinese Academy of Sciences (CAS) has validated the accuracy against extensive field surveys. An outdoor survey and random sample check (covering a line survey of 70,000 $\mathrm{km}$ and 13,300 patches) verified that the average interpretation accuracies for land-use/land cover were more than 92\% [19-21]. Consequently, the urban land in 2000 which comes from CAS can satisfy the precision requirement for analysis. A field survey, including approximate 125 sampling-points, was carried out by using a global positioning system to identify land-use histories in extracting the urban land for the other three years. Also, the Google map as well as the Second National Land-Use Survey Map was effectively used to check and identify the dynamic changes of land cover. Figure 2 and Table 1 present the urban land distribution pattern of the four years and its change information in the WUA region.

Figure 2. Urban land expansion process of four periods in the Wuhan Urban Agglomeration (WUA) region during 1980-2010.

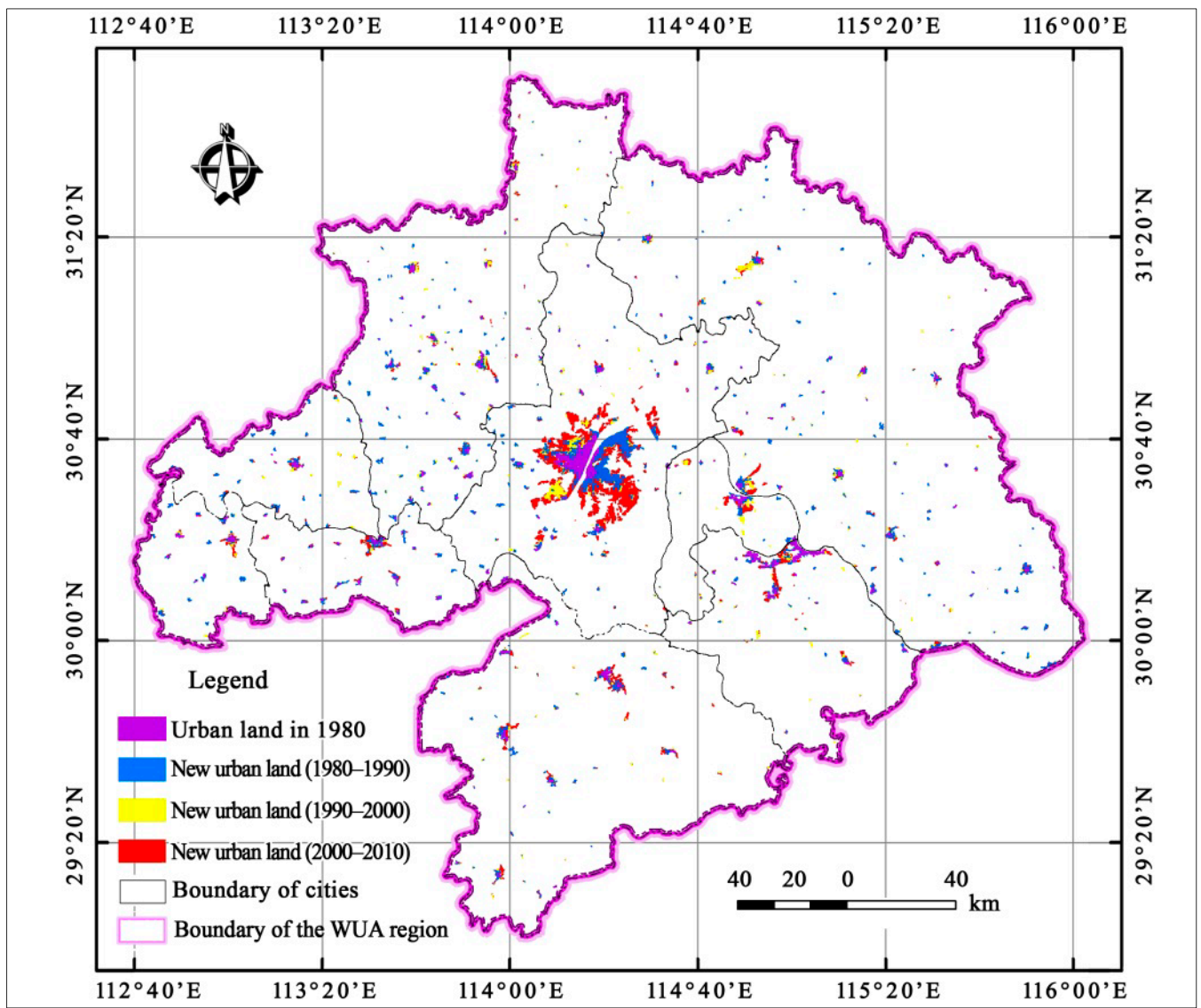


Table 1. The urban land area and its change of cities of different scales in the WUA region during the study period.

\begin{tabular}{lccccccc}
\hline \multirow{2}{*}{ Region } & \multicolumn{3}{c}{ Urban Land Area $\left(\mathbf{k m}^{\mathbf{2}}\right)$} & \multicolumn{3}{c}{ Urban Land Change $\left(\mathbf{k m}^{\mathbf{2}}\right)$} \\
\cline { 2 - 8 } & $\mathbf{1 9 8 0}$ & $\mathbf{1 9 9 0}$ & $\mathbf{2 0 0 0}$ & $\mathbf{2 0 1 0}$ & $\mathbf{1 9 8 0}-\mathbf{1 9 9 0}$ & $\mathbf{1 9 9 0 - 2 0 0 0}$ & $\mathbf{2 0 0 0 - 2 0 1 0}$ \\
\hline Wuhan & 88.28 & 272.58 & 336.89 & 715.40 & 184.3 & 64.31 & 378.51 \\
Huangshi & 33.43 & 56.54 & 66.22 & 96.98 & 23.11 & 9.68 & 30.76 \\
Ezhou & 7.43 & 17.47 & 27.75 & 44.97 & 10.04 & 10.28 & 17.22 \\
Xiaogan & 21.36 & 76.84 & 104.92 & 125.70 & 55.48 & 28.08 & 20.78 \\
Huanggang & 17.44 & 78.72 & 108.08 & 147.54 & 61.28 & 29.36 & 39.46 \\
Xianning & 15.89 & 48.35 & 59.26 & 104.28 & 32.46 & 10.91 & 45.02 \\
Xiantao & 9.69 & 30.95 & 35.66 & 60.83 & 21.26 & 4.71 & 25.17 \\
Qianjiang & 6.95 & 22.57 & 27.64 & 38.24 & 15.62 & 5.07 & 10.6 \\
Tianmen & 3.21 & 23.47 & 28.49 & 35.91 & 20.26 & 5.02 & 7.42 \\
WUA & 203.66 & 627.48 & 794.90 & 1369.83 & 423.82 & 167.42 & 574.93 \\
\hline
\end{tabular}

\subsubsection{Socio-Economic Data Acquisition}

Except for the LUCC data, we also obtained socio-economic data, including time-series data on population, industry, and urbanisation conditions in the whole region during the period 1980-2010. These data, which came from the Chinese City Statistical Yearbooks [7] and the Hubei Statistical Yearbook [16], were used to analyse potential influencing factors resulting in urban land expansion in the WUA region.

\subsection{Methods}

In order to explore and understand the spatio-temporal features of, and trends in, urban land expansion across the different decades, the urban expansion intensity index, the urban expansion differentiation index, and fractal correlation dimension measures were used in our study [15,22-24].

\subsubsection{Urban Expansion Intensity Index (UEII)}

The urban expansion intensity index (UEII) of a spatial unit is defined as the average annual proportion of newly increased urban area to its total area [22]. It refers to the average annual growth area standardised by the total area of the specific spatial unit. The UEII is calculated using the following Equation:

$$
U E I I_{i}=\frac{U L A_{i}^{t_{2}}-U L A_{i}^{t_{1}}}{T L A_{i} \times \Delta t} \times 100
$$

where $U E I I_{i}$ stands for urban expansion intensity index of unit $i, U L A_{I}^{t_{2}}$ and $U L A_{I}^{t_{1}}$ are the area of urban land at time $t_{2}$ and $t_{1}$, respectively, $T L A_{i}$ is the total area within the administrative county boundary $i$, and $\Delta t$ is the study period (i.e., $t_{2}-t_{1}$ ).

\subsubsection{Urban Expansion Differentiation Index (UEDI)}

The urban expansion differentiation index $(U E D I)$ refers to the ratio of the urban expansion rate of a spatial unit to the urban expansion rate of the study area. The UEDI quantifies the urban land 
expansion disparity between different spatial units, thereby making those units comparable, which is essential in evaluating regional urban land expansion differentiation and identifying urban land change hotspots [24]. We employ UEDI as the following:

$$
U E D I_{i}=\frac{\left|U L A_{i}^{t_{2}}-U L A_{i}^{t_{i}}\right| \times U L A^{t_{1}}}{\left|U L A^{t_{2}}-U L A^{t_{1}}\right| \times U L A_{i}^{t_{1}}}
$$

where $U E D I_{i}$ indicates the urban expansion differentiation index of unit $i$; $U L A_{i}^{t_{2}}$ and $U L A_{i}^{t_{1}}$ indicate the area of urban land of unit $i$ at time $t_{2}$ and $t_{1}$, respectively; and $U L A^{t_{2}}$ and $U L A^{t 1}$ indicate the total area of urban land in the study area at time $t_{2}$ and $t_{1}$, respectively.

\subsubsection{Fractal Dimension}

Fractal dimension measures constitute good instruments for global comparisons of the morphology of cities [15,23]. Fractal dimension includes radius dimension, grid dimension, correlation dimension, and boundary dimension. In our study, the correlation dimension $\left(D_{c}\right)$ was used to measure the uniformity degree of the urban distribution in the study area; it provides a detailed result in relation to the distribution pattern of occupied points. Two parameters, which vary according to the iterative step, are included in the correlation dimension: (a) the size of the counting window ( $\varepsilon$ ); and (b) the number of urban land pixels presented in the window $(N)$. The fractal law can be written as the following:

$$
N=\alpha \varepsilon^{D c}+\varphi
$$

where, $D_{c}$ represents the fractal correlation dimension; $\alpha$ is the "pre-factor of shape", which gives a synthetic indication of local deviations from the estimated fractal law; and $\varphi$ is a constant variable. Generally, $D_{c}$ is in the range of $0-2$. When $D_{c}$ is closer to 2, all towns are distributed more uniformly over space; when $D_{c}$ is closer to 0 , one premier city has been formed [15]. The $D_{c}$ can be obtained using the software Fractalyse developed by Gilles Vuidel.

In addition, the scaling behaviour curve $\alpha(\varepsilon)$ was introduced in order to identify the threshold at which the urban cluster morphology may change from one point to another [15]. The $\alpha(\varepsilon)$ can be written with the following Equation:

$$
N=\alpha \varepsilon^{\alpha(\varepsilon)}+\varphi
$$

\section{Results Analysis}

\subsection{The Temporal Evolution Characteristics of Urban Land Expansion}

Wuhan urban agglomeration has experienced a rapid urban land expansion process; the total area of urban land increased by 5.7 times-from $203.66 \mathrm{~km}^{2}$ in 1980 to $1370.07 \mathrm{~km}^{2}$ in 2010 (Figure 3). Increases in urban land area presented differently between cities of different scales (Table 2). As the central city of the metropolitan area, Wuhan showed the most rapid land expansion rate, by which the urban land area increased by 7.1 times in this period - from $88.28 \mathrm{~km}^{2}$ in 1980 to $715.40 \mathrm{~km}^{2}$ in 2010 . On the contrary, Qianjiang and Tianmen experienced the slowest land expansion speeds, increasing by merely $31.30 \mathrm{~km}^{2}$ and $32.70 \mathrm{~km}^{2}$, respectively, over the same period. Moreover, the rate of urban land expansion also presented differently during different periods. In the three decades, the urban land area 
of the WUA increased by $423.82 \mathrm{~km}^{2}, 167.42 \mathrm{~km}^{2}$, and $574.93 \mathrm{~km}^{2}$, respectively. Furthermore, the urban expansion intensity index (UEII) scores for the three periods were 0.0732, 0.0289, and 0.0993, respectively, exhibiting significant fluctuation; their corresponding coefficient of standard deviation amounted to $0.7538,0.7767$, and 1.3430 , respectively, demonstrating that regional differences in urban expansion intensity increased during the study period.

Figure 3. The total urban land and its change in the WUA during the study period.

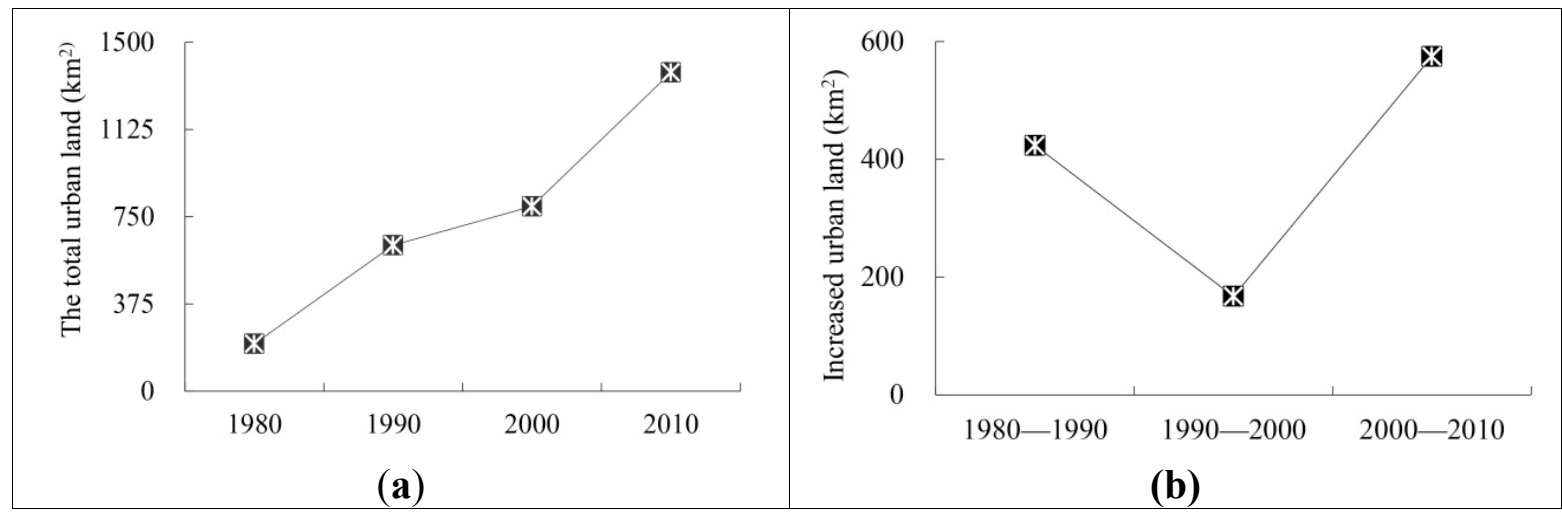

Table 2. Urban expansion intensity index and urban expansion differentiation index in the WUA region during the study period.

\begin{tabular}{lcccccccc}
\hline \multirow{2}{*}{ Region } & \multicolumn{3}{c}{ Urban Expansion Intensity Index(UEII) } & \multicolumn{3}{c}{ Urban Expansion Differentiation Index(UEDI) } \\
\cline { 2 - 8 } & $\mathbf{1 9 8 0 - 1 9 9 0}$ & $\mathbf{1 9 9 0 - 2 0 0 0}$ & $\mathbf{2 0 0 0 - 2 0 1 0}$ & $\mathbf{1 9 8 0 - 2 0 1 0}$ & $\mathbf{1 9 8 0 - 1 9 9 0}$ & $\mathbf{1 9 9 0 - 2 0 0 0}$ & $\mathbf{2 0 0 0 - 2 0 1 0}$ & $\mathbf{1 9 8 0 - 2 0 1 0}$ \\
\hline Wuhan & 0.2167 & 0.0756 & 0.4450 & 0.7372 & 1.0032 & 0.8842 & 1.5534 & 1.2406 \\
Huangshi & 0.0508 & 0.0213 & 0.0676 & 0.1397 & 0.3323 & 0.6414 & 0.6423 & 0.3320 \\
Ezhou & 0.0616 & 0.0630 & 0.1056 & 0.2302 & 0.6495 & 2.2055 & 0.8582 & 0.8827 \\
Xiaogan & 0.0625 & 0.0316 & 0.0234 & 0.1175 & 1.2484 & 1.3695 & 0.2738 & 0.8532 \\
Huanggang & 0.0352 & 0.0169 & 0.0226 & 0.0747 & 1.6883 & 1.3983 & 0.5047 & 1.3027 \\
Xianning & 0.0333 & 0.0112 & 0.0462 & 0.0908 & 0.9814 & 0.8462 & 1.0502 & 0.9713 \\
Xiantao & 0.0842 & 0.0186 & 0.0996 & 0.2024 & 1.0545 & 0.5695 & 0.9761 & 0.9217 \\
Qianjiang & 0.0772 & 0.0250 & 0.0524 & 0.1546 & 1.0809 & 0.8421 & 0.5304 & 0.7869 \\
Tianmen & 0.0768 & 0.0190 & 0.0281 & 0.1239 & 3.0371 & 0.8018 & 0.3598 & 1.7812 \\
WUA region & 0.0732 & 0.0289 & 0.0993 & 0.2014 & 1.0000 & 1.0000 & 1.0000 & 1.0000 \\
Coefficient of & & & & & & & 1.5534 \\
standard & 0.7538 & 0.7767 & 1.3430 & 0.7538 & 1.0032 & 0.8842 & 1.2406 \\
deviation & & & & & & &
\end{tabular}

\subsection{The Spatial Evolution Characteristics of Urban Land Expansion}

Spatially, urban land expansion was characterised by conspicuous concentrations and regional imbalances during the study period. As a core city, Wuhan was the centre of the ring-layer expansion patterns in the WUA region (Figure 2). The urban land area of the city increased by $627.12 \mathrm{~km}^{2}$ during the study period, contributing to $53.78 \%$ of the total urban expansion of the WUA region (Table 1). The urban land-use expansion generally intensified along the Third Ring Road of Wuhan, the Beijing-Guangzhou railroad, and other main transportation corridors. The urban expansion pattern presented different features at different stages in the WUA region. During 1980-1990, 1990-2000, and 
2000-2010, the urban land expansion of the WUA exhibited the distribution pattern of "one pole and four belts", "one pole and one belt", and "three poles and six belts", respectively [25].

In order to reveal the spatial evolution pattern of urban land expansion, the urban expansion differentiation index (UEDI) scores of the 39 districts/counties that make up the region were grouped into five UEDI zones, i.e., higher, high, medium, low, and lower, based on the Nature Break method with the application of software ArcGIS. The higher and high UEDI zones referred to the districts/counties with a higher urban land expansion rate than that of the study area; the medium UEDI zone consisted of the districts/counties with essentially the same urban land expansion rate as the overall area; while the low and lower UEDI zone designated districts/counties with lower urban land expansion rates than that of the study area (Figure 4).

Figure 4. The spatial characteristics of urban expansion differentiation index (UEDI) in the WUA.

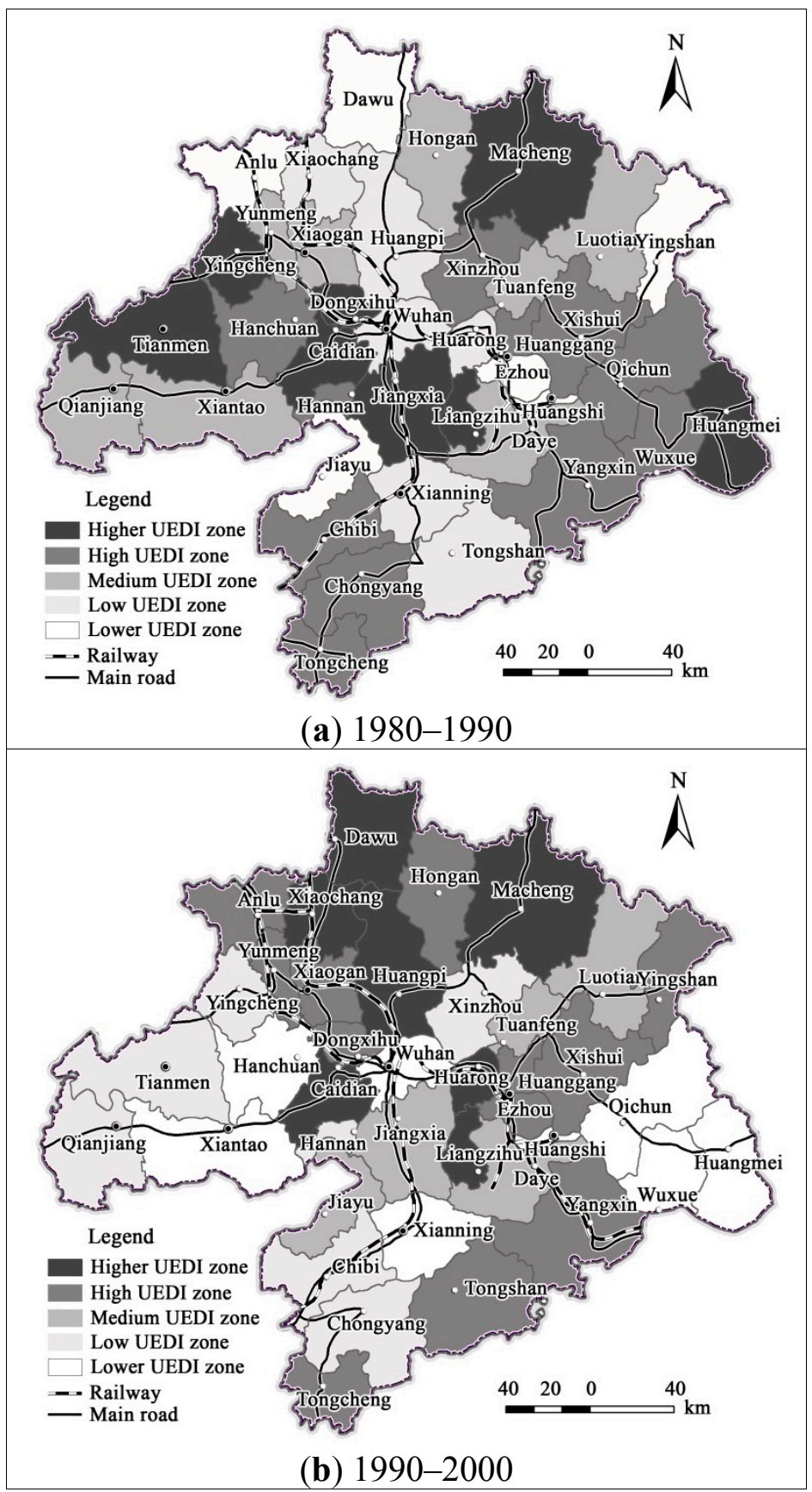


Figure 4. Cont.

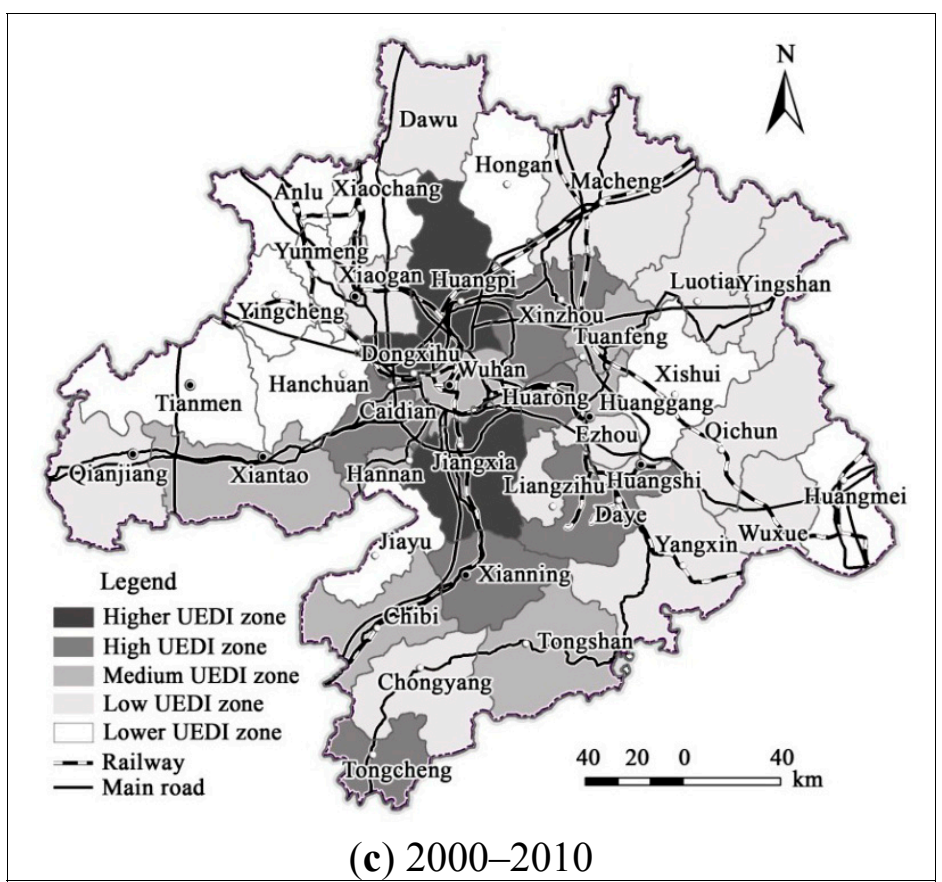

The spatial differentiation characteristics of urban land expansion in the period 1980-1990 are presented at Figure 4a. The pattern of urban expansion from this period displays significant spatial correlation and conspicuous concentration. The higher and high UEDI zone formed an east-west band across the WUA region, shaping an obvious axial distribution pattern. A large number of small and medium-sized cities/counties (such as Tianmen, Yingcheng, Macheng, and Hanchuan in the Jianghan Plain area, and the eastern plain of Hubei Province) underwent rapid urban expansion. By contrast, the UEDI of the central cities-i.e., Wuhan, Huangshi, Ezhou, and Xianning — was significantly lower than that of the surrounding small districts/counties.

Figure $4 \mathrm{~b}$ shows the spatial characteristics of urban land expansion in the study area between 1990 and 2000. In contrast to the previous decade, the east-west axis of urban land expansion was replaced in this decade by expansion in a north-south direction, which became the primary location of the higher and high UEDI zone. Urban expansion in the north-south direction exhibits a zonal distribution formation along the main traffic axis (the urban extension axis following the Beijing-Guangzhou railroad) and secondary traffic axis (the urban extension axis along Huangshi-Huanggang line). By contrast, the districts/counties located in the Jianghan plain and the eastern plain of Hubei Province, which used to be the active urban expansion centres during 1980-1990, presented slow urban land growth rates in the following decade.

In the third period, the spatial pattern of urban expansion shows distinctive characteristics that mark an evolution from the previous two decades (Figure 4c). The higher and high UEDI zone was concentrated in the centre of Wuhan, within a radius of $50 \mathrm{~km}$. The urban expansion differentiation index of the central cities - i.e., Wuhan, Huangshi, Ezhou, Huanggang, and Xianning-was significantly higher than that of the overall area. Further, the higher and high UEDI zone shaped a typical zonal distribution pattern that followed transport axes; whilst urban land expansion rates along the main traffic arteries of the Beijing-Guangzhou mainline and the Shanghai-Chengdu line were 
significantly high, counties located far away from the main traffic lines experienced slow rates of urban land expansion.

\subsection{The Spatio-Temporal Evolution of Urban Morphology}

Figure 5 shows the global fractal correlation dimension (GFCD) as well as the scaling behaviour in the WUA region across the four years addressed by the study. The GFCD was the largest (i.e., 1.371) in 1980, indicating that the urban land exhibited a homogeneous spatial distribution pattern. The local fractal correlation dimension (LFCD) in this year presented a large fluctuation, from about $0.3-1.8$ for different estimation intervals, showing a heterogeneous spatial organisation, especially in the $\varepsilon$ ranges of 25-250 and 400-500 pixels, a result of LFCD values of less than 1. The GFCD was 1.148 in 1990 and 1.172 in 2000, respectively, indicating that the distribution of urban land in these two years was characterised by conspicuous concentrations and regional imbalances. Moreover, the LFCD in 1990 and 2000 retained similar values at different estimation intervals; this finding can be explained by the fact that the WUA region experienced a slow urban land expansion in this decade, and the distribution pattern of urban land basically did not change. The GFCD was smallest in 2010 (equal to 0.9112), demonstrating that urban land had become more concentrated in comparison to the preceding three years. This is in accordance with the results of the study, which indicate that Wuhan had concentrated more than $52.23 \%$ of the total urban land in the WUA region.

Figure 5. (a) Fractal correlation dimension, $x$-axes for time (in year), left $y$-axis and solid black diamond for correlation dimension, right $y$-axis and hollow white rectangle for correlation coefficient; (b) the scaling behaviour, $x$-axis for the size of the counting window $\varepsilon$ (in pixel), $y$-axis for the "pre-factor of shape" $\alpha$.

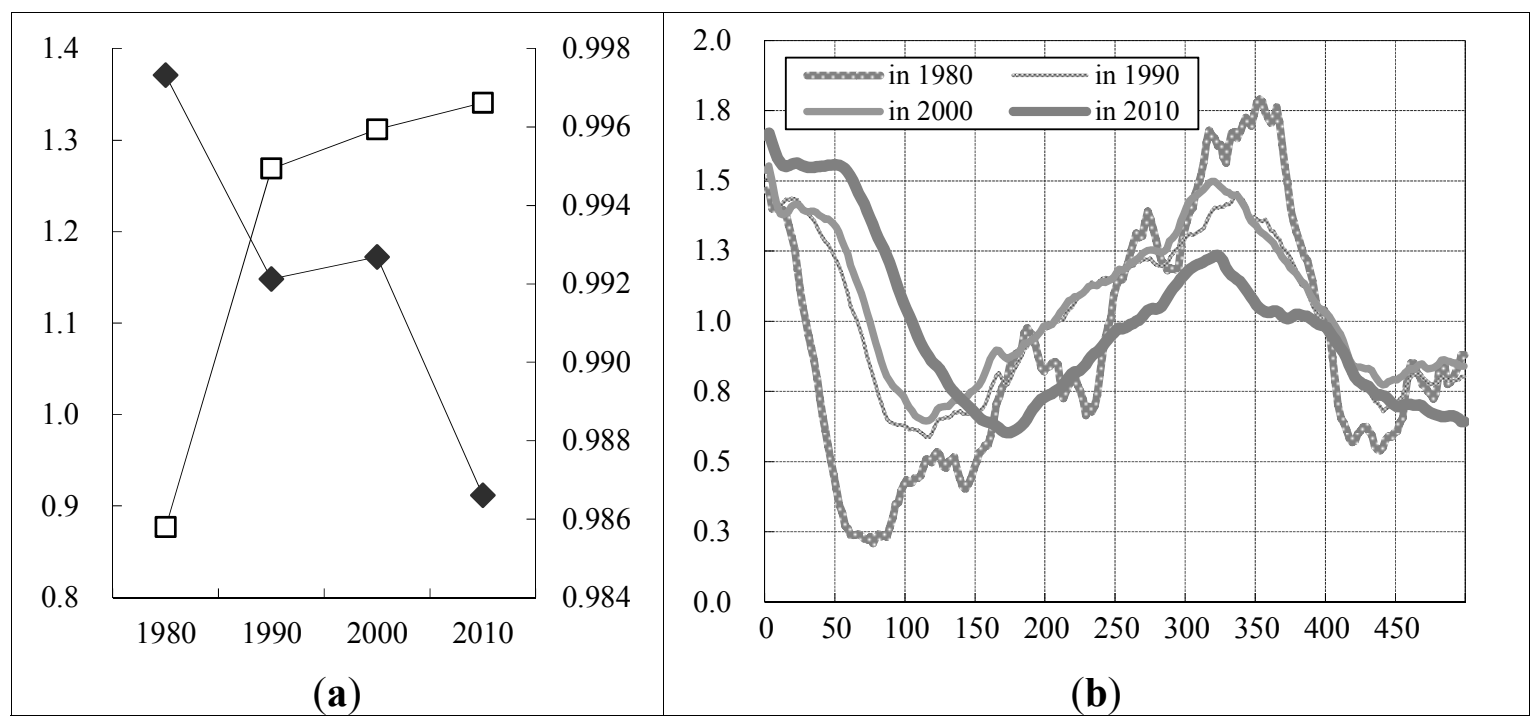

\section{Factors Influencing Urban Land Expansion}

Referring to previous studies [11,12,14,26,27], we argue that industrialisation and urban population growth are the basic driving factors that directly influence urban land expansion. Meanwhile, institutional factors-including land-use policies, urbanisation guidelines (governmental plans and 
regulations addressing urbanisation) — and the national development strategy, which directly impact upon economic growth and urbanisation processes, constitute the important influencing factors in relation to temporal fluctuation and spatial differentiation in urban land expansion. The effects of each of these factors have been specifically explored in our study: a discussion of each is presented below.

\subsection{Industrialisation}

Industrialisation is one of the most important driving forces behind urban land expansion. The increasing demand for urban land is commonly known to derive from urban-related industrialisation, i.e., urban settlements and manufacturing development in China [28]. Since the initiated economic reforms and the open-door policy, industrialisation has accelerated in the WUA region, as evidenced by the continuous growth of the region's total industrial output value (Table 3).

Table 3. The socioeconomic indicators in the WUA region for the four years.

\begin{tabular}{lcccc}
\hline \multicolumn{1}{c}{ Indicators } & $\mathbf{1 9 8 0}$ & $\mathbf{1 9 9 0}$ & $\mathbf{2 0 0 0}$ & $\mathbf{2 0 1 0}$ \\
\hline Gross domestic product (GDP) $/ 10^{8} \mathrm{RMB}$ & 114.08 & 386.64 & 2499.13 & 9635.76 \\
GDP per capita/RMB & 478 & 1429 & 8142 & 31861 \\
Total population $/ 10^{4}$ persons & 2384.81 & 2704.91 & 3069.60 & 3024.29 \\
Urbanisation rate $\%$ & 20.91 & 26.15 & 46.09 & 53.10 \\
Total industrial output value $/ 10^{8} \mathrm{RMB}$ & - & 619.78 & 1844.05 & 13146.42 \\
Total fixed asset investment $/ 10^{8} \mathrm{RMB}$ & - & 75.31 & 806.81 & 6762.67 \\
\hline
\end{tabular}

Notes: The socioeconomic indicators come from Hubei Statistical Yearbook of the corresponding year; "-" indicates that data is missing.

It is noted that the construction of the economic development zone (EDZ) inevitably leads to changes in the structure of land use, especially with respect to the expansion of urban land area. As an important spatial carrier of industrial activities, EDZs attract both domestic and foreign investment and aggregate population, capital, information, industry and other factors at large scales, due to their incomparable policy privileges and socioeconomic development advantages, which are superior to those offered by other regions [12]. Taking Wuhan as a case, there were three national EDZs and 12 provincial EDZs (Figure 6). Statistical data shows that foreign direct investment, total industrial added value, and the total export value of the EDZs in Wuhan respectively reached $85.81 \times 10^{8} \mathrm{RMB}$, $1798.14 \times 10^{8} \mathrm{RMB}$, and $251.95 \times 10^{8} \mathrm{RMB}$ in 2010 , equal to a $58.4 \%, 86.5 \%$, and $45.1 \%$ share of the corresponding total value in Wuhan, respectively [16]. The construction and development of EDZs consolidates Wuhan's industrialisation as well as urbanisation, as evidenced by rapid increases in the area of EDZs - from $137.21 \mathrm{~km}^{2}$ in 2006 to $217.62 \mathrm{~km}^{2}$ in 2010 . Actually, EDZs accounted for more than $30 \%$ of the total urban land area in 2010 .

As the core city of the WUA region, Wuhan has a strong control ability and leading role in socioeconomic development of this region. The gross domestic product of the city in 2010 exceeded 550 billion RMB, equal to a $57.76 \%$ share of the corresponding total value in the WUA region [16]. As such, taking the city of Wuhan as an example, we analysed the relationship between industrialisation and urban land expansion. Since 1978, Wuhan has become the most important economic and industrial centre in the middle reach of Yangtze River. In 1984, the city was approved to 
be the pilot city for the country's economic system reform. Wuhan municipal government began to adjust the development mode in relation to the existing industrial enterprises. During this process, the city established the East Lake new technology development zone, Wuchang economic development zone, and Qingshan economic development zone, which were huge enclaves far away from the urban central district (Figures 6 and 7). Motivated by the economic law of location rent in an urban land market, many industrial enterprises, located in the urban central district in the former administrative system, were gradually relocated to these EDZs in suburban or rural areas while the original central sites were transferred to use in the tertiary sector [22]. These resulted in a continuous spatial expansion surrounding the urban central district (Figure 7). In this period, the gross value of industrial output and urban land increased from 101.00 billion RMB in 1980 to 303.15 billion RMB in 1990 and from $88.28-272.58 \mathrm{~km}^{2}$, respectively.

Figure 6. The distribution pattern of the Economic Development Zones (EDZs) and urban land of Wuhan in 2010.

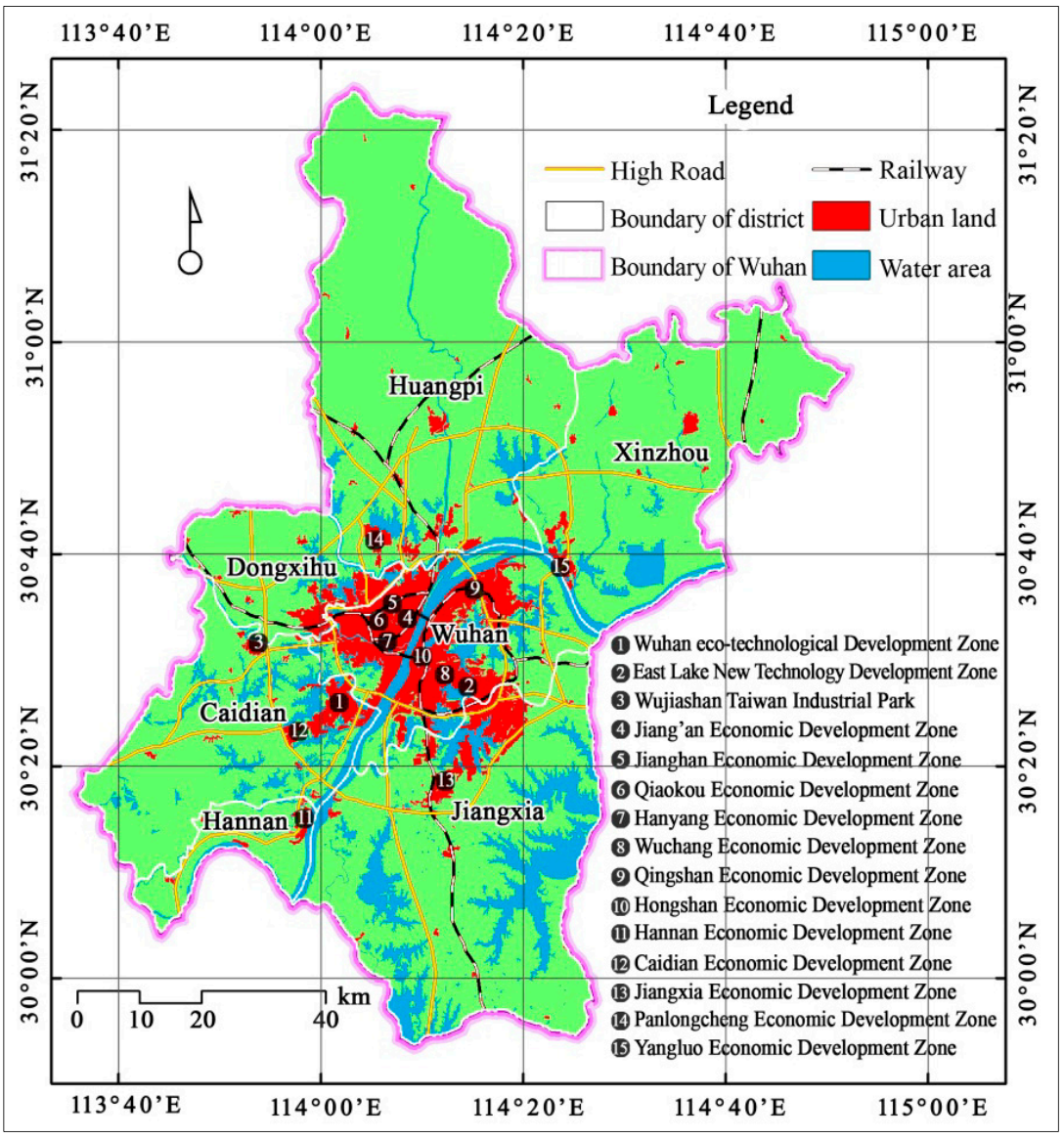

During the second decade 1990-2000, the coastal region of China became the country's economic development centre. The WUA region, which was located in the central region, presented extremely slow development. In this decade, Wuhan municipal government only constructed the Wuhan economic and technological development zone (Figures 6 and 7). The city was characterised as infill development, such as, the improvement of infrastructure and city function, the promotion of industrial technology, and the increase of service industry, with a slow urban land expansion-from $272.58 \mathrm{~km}^{2}$ in 1990 to $336.89 \mathrm{~km}^{2}$ in 2000 . 
Figure 7. The spatial expansion pattern in the city of Wuhan during the three periods.

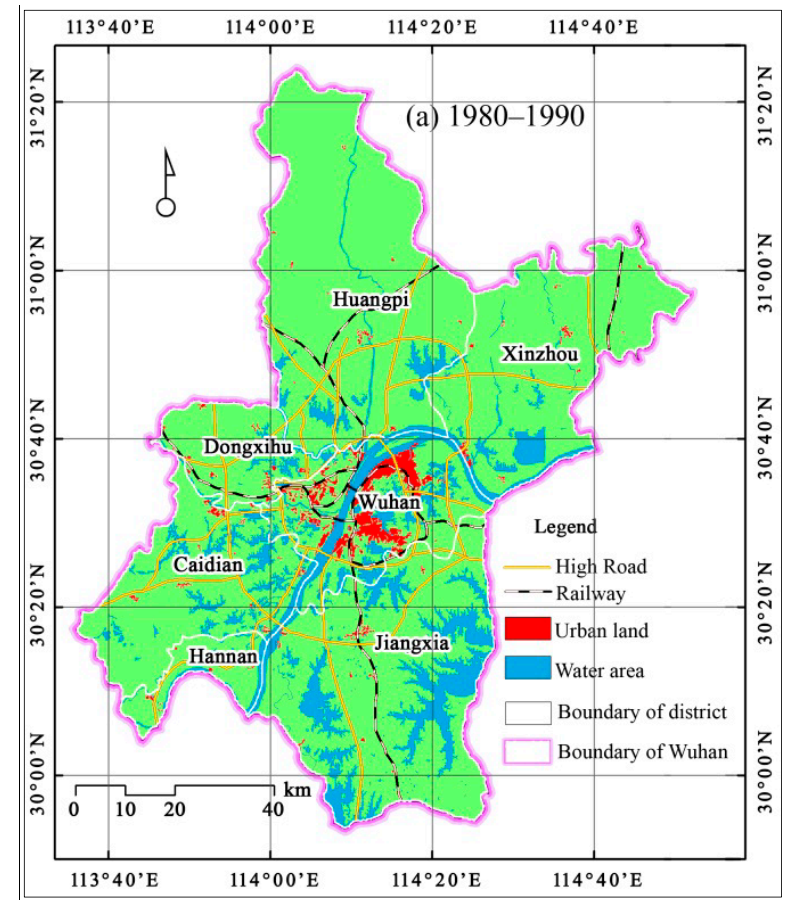

(a) $1980-1990$

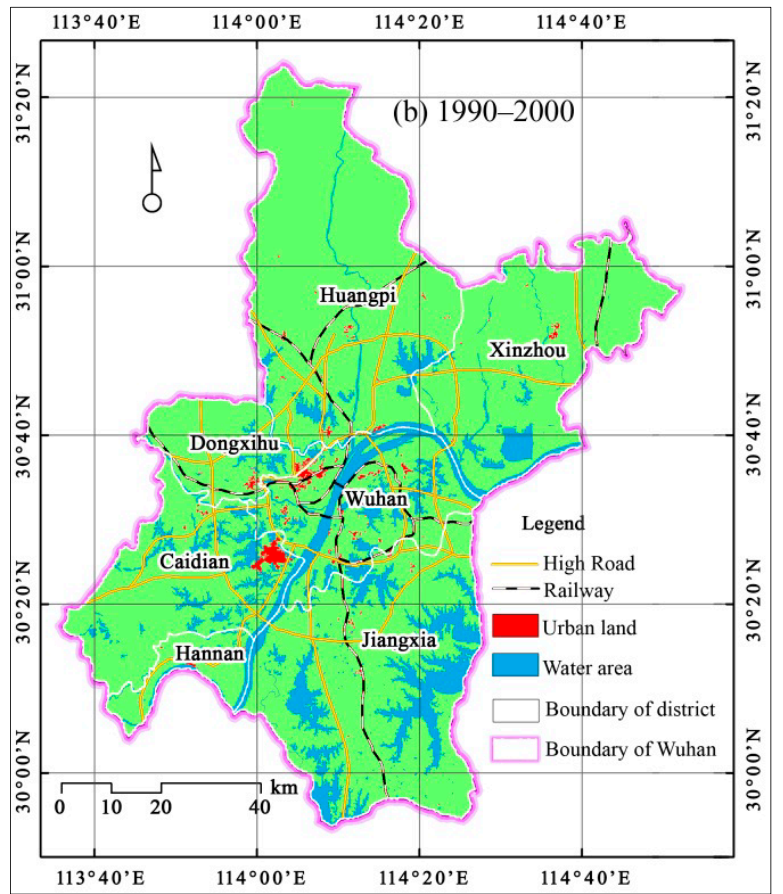

(b) $1990-2000$

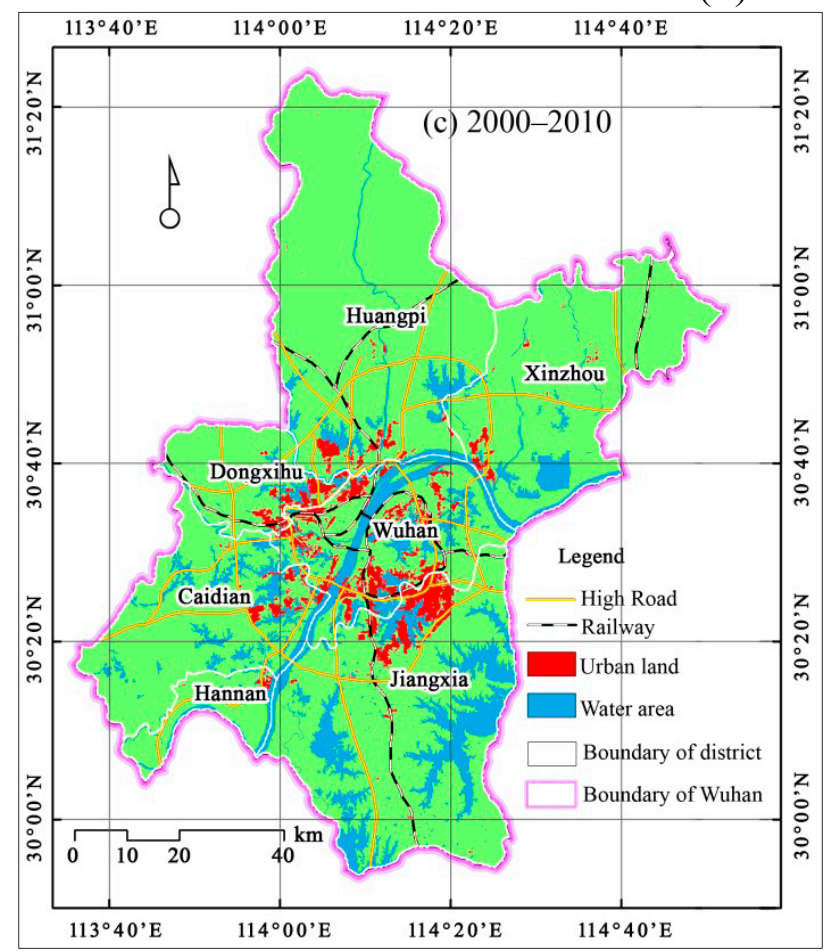

(c) 2000-2010

In the new millennium, Wuhan has begun to enter into a phase with the most rapid socioeconomic development in the history. The industry in this city speeded up the process of Wuhan's integration into the global economic system; the city has formed four pillar industries, i.e., steel industry, automobile and machinery manufacturing industry, electronics information industry, and petroleum chemical industry. Meanwhile, Wuhan has also bred six competitive industries, i.e., environmental protection industry, tobacco and food industry, household appliances industry, textile industry, 
medicine industry, papermaking and packaging industry. Under this context, Wuhan has basically formed a new industrial system with comprehensively competitive advantages, and has successfully realized the transition from an old industrial base to an advanced manufacturing base [29]. In this period, Wuhan has constructed Jiangxia, Hannan, Caidian, Yangluo and Panlongcheng economic development zones (Figure 6). The gross value of industrial output increased from 142.24-700.50 billion RMB. In response to the rapid industrialisation, the city's urban land expanded from $336.89-715.40 \mathrm{~km}^{2}$ (Figure 7).

\subsection{Urban Population Growth}

Urban population changes in relation to urbanisation constitute one of the most dynamic causes of land-use change, triggering changes in land-use intensity and land-use structure [27]. Since 1978, the collapse of the "People's Commune" system and the subsequent implementation of the Household Responsibility System in rural areas restored greater liberty to farmers and mass rural-to-urban migration, as migrants were free to seek jobs and earn their living in cities. The development of urban infrastructure and a flourishing small-business environment required extra labour-these sources of employment have accommodated the vast movement of agricultural labour from rural areas to cities in China since the 1980s [30]. The explosive growth of urban populations and the improvement of urban residents' living standards inevitably leads to increased needs in terms of housing and transportation; this in turn greatly stimulates the development of the real estate industry and of transportation, both of which encroach upon agricultural land and lead to urban land expansion. Statistical data shows that the country's urban population increased from $19,140 \times 10^{4}$ in 1980 to $66,978 \times 10^{4}$ in 2010 , the average number of vehicles per hundred households increased from $0.1-13.1$, and the per capita living space jumped from $6.7-31.6 \mathrm{~m}^{2}$, respectively [7].

The WUA region has also experienced unprecedented rates of urbanisation in the past 30 years, which played an important role in the expansion of urban land. The urban population of the region expanded by 2.22 times in that time-from $498.66 \times 10^{4}$ people in 1980 to $1605.98 \times 10^{4}$ people in 2010; the corresponding urbanisation rate increased by 32.19 percentage points, from $20.91 \%$ to $53.10 \%$. The large scale of urban population growth has caused the urban expansion of the region, which has witnessed an increase of $1166.17 \mathrm{~km}^{2}$ in its total urban land area-from $203.66 \mathrm{~km}^{2}$ in 1980 to $1369.83 \mathrm{~km}^{2}$ in 2010 .

In addition, the 39 districts were divided into four zones based on urban population growth (i.e., high growth zone, moderate growth zone, low growth zone, and lower growth zone) so as to examine the spatial correlation between population growth and urban expansion in the WUA region in the period 2000-2010. The results indicate that the high urban population growth zone, which is composed of Wuhan downtown and Huangshi downtown, witnessed an increase in urban population and urban land of $192.43 \times 10^{4}$ people and $149.01 \mathrm{~km}^{2}$, accounting for $28.11 \%$ and $21.77 \%$ of that in the WUA region. The moderate growth zone, which includes medium cities of Daye, Hanchuan, Xiantao, Tianmen, experienced an increase in urban population and urban land of $29.17 \times 10^{4}$ people and $21.25 \mathrm{~km}^{2}$. The urban population growth and urban land expansion in low growth zone and lower growth zone reached $18.63 \times 10^{4}$ people and $7.12 \times 10^{4}$ people, $10.19 \mathrm{~km}^{2}$ and $5.46 \mathrm{~km}^{2}$, respectively. It can be seen that there was a great spatial coupling relationship and a strong positive correlation between urban 
population growth and urban land expansion in the study area. It is worth noting that the intensity of urban land expansion in the surrounding suburbs of Wuhan was significantly higher than that of urban population growth. The data indicates that, the urban population in the districts of Jiangxia, Dongxihu, Caidian, Huangpi, Xinzhou increased by $81.96 \times 10^{4}$ people in the period $2000-2010$, accounting for $11.97 \%$ of that in the metropolitan area. However, the total of the newly increased urban land reached $224.05 \mathrm{~km}^{2}$, accounting for more than $38.97 \%$ of that in the WUA region. Undoubtedly, the surrounding area of Wuhan has experienced a low density of urban land expansion. The land managers should raise awareness that the WUA region has experienced a particularly vigilant of low-density development and urban sprawl.

\subsection{Land-Use Policies}

Land-use policies have also contributed to temporal variation in, and geographic differentiation of, urban land expansion in the WUA region [26,27]. In the first half of the 1980s, China's land management system was decentralised. Rural land was to be managed by the Ministry of Agriculture, while urban land was to be managed by the Ministry of Construction. As a result of these changes, the transition between urban and rural land basically remained frozen in this period. In the second half of the 1980s, land reform in China created a property market, which re-introduced land values through land leasing and charging of land use fees [31]. In addition to a growing interest in real estate development, coupled with the release of rural productivity and the boost of reform and opening up, urban land expansion was also stimulated by rapid socio-economic development in the region. Under these circumstances, the Chinese Government promulgated and implemented the "Land Administration Law of the People's Republic of China", and the land market system began to take shape [32]. The transition to different land-use types in the WUA region was thus intensified as a result of the deepening of land reforms in the late 1980s, and the region experienced a rapid transition from rural to urban land during this decade.

During the second period studied, a large number of restrictive land policies were mapped out in succession in response to the transition from the planned to the market-oriented institution, as well as the accelerated land-use change [33]. From the late 1980s to the early 1990s (especially after Deng's southern China tour in 1992), in order to produce the greatest economic benefit from the land and thus fulfil the pursuit of economic growth, urban land area expansion continuously accelerated. The loss of valuable agricultural land caught the attention of the central government. Against this backdrop, the State Council promulgated the Regulations for the Protection of Basic Farmland (Jiben Nongtian Baohu Tiaoli) in 1994. By 1997, a directive from the central government urgently appealed for the conservation of farmland and ordered the freezing of all construction projects. A year later, a new but more stringent Land Administration Law was enacted to prevent further loss of arable land [34]. Because of the austere situation with respect to arable land, the Chinese Government issued the revised Land Management Act (The Land Management Act of China) and Protection Ordinance of Basic Farmland (New Jiben Nongtian Baohu Tiaoli) in 1998 to ensure sustainable socio-economic development [14]. It can be seen that since 1994, a series of severe regulations and laws have been implemented to prevent excess loss of arable land. These laws curtailed the haphazard exchange of 
farmland for urban land [33]. The influence of these restrictive land-use polices was profound in slowing the expansion of urban land area in the WUA region.

Following the Asian financial crisis, and especially since 2002, China's economic development has begun to enter into an acceleration phase of rapid industrialisation and urbanisation. The rapid economic development incited strong growth in urban land area, causing considerable loss of arable land [34]. Against this background, the central government issued a large number of pieces of more stringent farmland protection legislation, including "drawing up land-use planning", and "ensuring the arable land protection red line of 18 million mu" [14]. However, in order to simultaneously meet construction land demand in support of the rapid economic development, the government also drew up more flexible policies such as "pushing forward urban construction land increase and rural construction land decrease balance" (i.e., zengjian guagou) and "achieving dynamic equilibrium of the total arable land" (i.e., gengdi zhanbu pingheng) [12]. Consequently, urban land expansion in the WUA region was not actually held back during this stage, because the huge quantity of farmland consumed by the development of EDZs and real estate zones could be balanced with land reclamation and rural construction land decrease through land rehabilitation.

\subsection{Urbanisation Guidelines}

Because cities can provide noticeably higher income and more employment opportunities than rural areas, huge numbers of peasants have migrated from rural to urban areas in China. In order to deal with the pressures from urban in-migration, a strict Hukou system-similar to a domestic passport system - was established in the pre-reform era in China [14,35]. However, in reality, the Hukou system failed to control the population explosion and economic dominance of the large cities in terms of globalisation, urbanisation economies, increasing returns, and element agglomeration [36]. In this context, urbanisation guidelines - that is, the various governmental plans and regulations addressing urbanisation brought forward by the State Council of China at various stages of development-were implemented to guide the Chinese urban system. Undoubtedly, these guidelines have had an important influence on economic development, population growth, and the urban expansion of cities at a range of scales.

In detail, during the sixth and seventh "Five-Year Plan Period" (1980-1990), the urbanisation guidelines can be generally described as having strictly controlled the scale of large cities, rationally developed medium-size cities, and actively encouraged the development of small cities [37]. These urbanisation guidelines stimulated urban population increases and economic growth in small cities, and deprived large cities of some development opportunities. Correspondingly, small and medium-sized cities/counties enjoyed significantly higher urban expansion intensity than that of the central cities in the WUA region; Tianmen, Yingcheng, Macheng, and Hanchuan predominantly became the active centres of urban expansion during this period.

During the "Eighth and Ninth Five-Year Plan Period" (1990-2000), in addition to putting forward an important strategy of promoting the healthy development of small towns, urbanisation guidelines were basically consistent with those of the preceding decade. Urbanisation guidelines exerted limited impact on the urban land expansion pattern in the WUA region at this stage, due to the fact that 
economic policies and national development strategy favoured the coastal region, and therefore slowed the central region's economic development and corresponding urban expansion [37].

During the "Tenth and Eleventh Five-Year Plan Period" (2000-2010), the Chinese Government mapped out a strategy to accelerate the urbanisation process, and harmoniously developing large, medium, and small cities, as well as small towns. Especially entering into the "Eleventh Five-Year Plan Period", the central government was committed to strengthening the leading role and improving the socio-economic function of the regional central cities; urban agglomeration gradually became the main battlefield upon which the struggle to speed up the urbanisation process would take place. Correspondingly, the Wuhan urban agglomeration (WUA) served as the most dynamic potential core area for economic development, population concentration, and industry aggregation in central China. During this period, the WUA region witnessed great achievements in economic construction and social development; the proportion of the WUA region's GDP in comparison to Hubei's increased by 2 percentage points, from $58.4 \%$ in 2000 to $60.4 \%$ in 2010 . As the growth engine of the WUA region, Wuhan was entitled to socio-economic development advantages superior to those offered to other regions. The city's GDP managed to rise from $1206.84 \times 10^{8} \mathrm{RMB}$ in 2000 to $5565.93 \times 10^{8} \mathrm{RMB}$ in 2010; its average annual growth rate was 2 percentage points higher than that of the WUA region. The urban land area of the city increased by $378.51 \mathrm{~km}^{2}$, contributing to $65.84 \%$ of the total urban expansion of the WUA region. In contrast, the city's share of total urban expansion in the previous two stages was merely $43.49 \%$ and $38.41 \%$. The fractal correlation dimension $\left(D_{c}\right)$ also demonstrates that the urban land in 2010 exhibited a heterogeneous and concentrated spatial distribution pattern. This development indicates that central cities began to dominate the urbanisation process following the implementation of the "metropolitan development strategy".

\subsection{National Development Strategy}

National development strategy has been demonstrated to be one of the main factors influencing urban land expansion in China [6,10,12,14]. In the Maoist periods (1949-1978), China's regional development strategy attached more emphasis to the eradication of regional economic disparities through interior-orientated investments than is done today. The "Maoist development strategy" has, however, been recognised as slowing national economic growth by ignoring scale and external economies [38]. During the post-Mao periods, China adopted industrial and urban priority development strategies. As we all know, China has made great achievements in economic and social development after 1978 as a result of its "uneven development strategy", which emphasised intensive modes of economic growth, highlighted regional comparative advantage, accepted regional disparities as inevitable, encouraged foreign direct investment and international interaction, and sought technological innovation [39].

In 1980, the State Council approved Wuhan's status as a foreign trade port and reopened Wuhan Customs. The city was also approved to be the pilot city for the national economic system reform in 1984. Thus, Wuhan became a quasi-province-level city as well as an important economic centre in the middle reaches of the Yangtze River. Meanwhile, Wuhan municipal government put forward a serial of development strategies such as the "Grow-Up Strategy for Transportation and the Logistics Industry", and "Promoting the Economic Integration between Urban and Rural Areas", which 
invigorated the market and improved economic linkages between Wuhan and adjacent regions. In response to the aforementioned series of polices, the WUA region experienced vital, rapid economic development, which contributed to a rapid urban land expansion. As a result, the urban expansion intensity index (UEII) reached 0.0732 in the WUA region and urban expansion shaped the "one pole and four belts" distribution pattern in this period.

However, China's regional economic inequality, particularly between coastal and interior region, was at a high level, and continued to expand due to the "uneven development strategy". Since China initiated the policy of opening and developing Pudong, Shanghai, in 1990, the eastern coastal region has been the "engine of growth" driving China's economic development. By contrast, economic development in central and western China was slow, with these areas even being referred to as “Central Sunken". During this period (1990-2000), the urban land expanded by merely $167.43 \mathrm{~km}^{2}$ in the WUA region, accounting for $39.50 \%$ and $29.10 \%$ of the urban land increase in the first and third period, respectively. The urban expansion intensity index (UEII) was 0.0289 in the WUA region and the "one pole and one belt" spatial expansion pattern of urban land use was formed in this stage [25]. The urban land expansion along the traffic trunk road presented a "resting" status.

Undoubtedly, the interior region has contributed greatly to, and has made substantial sacrifices for, the development of coastal regions in China since 1978. In order to narrow the inter-regional gap, the central government of China formulated the "Western Development Strategy" in 1999, "Reinvigorating Old Industrial Bases of Northeast China" in 2003, and the "Central Region Grow-Up Strategy" in 2006 in order to gear up economic growth in central and western regions following the turn of the new millennium. In line with Hubei Province's proposal to construct the " $1+8$ Wuhan chengshi quan" (i.e., the Wuhan urban agglomeration), on 8 November 2003, the State Council formally approved the Wuhan urban agglomeration as the comprehensive reform pilot area of "National Resource-saving and Environment-friendly Society Construction" on 14 December 2007. These development strategies have promoted the regional economic prosperity and integration of the WUA region immensely. During this period, the study area was full of vigour and vitality, becoming one of the most intensified urbanisation areas in central China; subsequently, the total area of urban land increased by $575.16 \mathrm{~km}^{2}$ over the course of the decade-from $794.91 \mathrm{~km}^{2}$ in 2000 to $1370.07 \mathrm{~km}^{2}$ in 2010 . The urban expansion intensity index (UEII) reached 0.0993 and the "three poles and six belts" spatial expansion pattern of urban land use was shaped in the WUA region [25]. Undoubtedly, the WUA region met a new high and inevitable tide of socio-economic boom and urban land expansion.

\section{Discussion}

Generally, urban land expansion relates to a number of social, economic, national, and regional development strategies and policy factors, as well as their interactions. It can be contended that urban land expansion in both central China and eastern China are driven by the similar or same factors. However, the spatio-temporal pattern of urban land expansion might exhibit different characteristics between central and eastern regions due to the fact that the same driving factors might have a different or an opposite influence on economic growth and urbanisation in different regions. For instance, national development strategy in 1990s (e.g., prioritised eastern/coastal development strategy) has accelerated the economic growth and urban land expansion of the eastern region, but having a negative 
influence on the process of industrialisation and urbanisation in the central region. This can be evidenced by the previous studies; the annual increased urban land in the period 1990-2000 of Guangzhou (located in Pearl River Delta) and Shanghai (located in Yangtze River Delta) was $16.32 \mathrm{~km}^{2}$ and $69.70 \mathrm{~km}^{2}$ [40,41], which was much faster than that in Wuhan (only $6.43 \mathrm{~km}^{2}$ ). However, the annual increased urban land of Wuhan was $37.85 \mathrm{~km}^{2}$ in the period 2000-2010, which is 1.71 times higher than that in Guangzhou $\left(22.19 \mathrm{~km}^{2}\right)$. It can be concluded that the dynamic patterns of urban land expansion in the WUA region is significantly different from those metropolitan areas in the eastern region of China. It is necessary to analyse and compare the intensity of urban land expansion of metropolitan areas located in both central and eastern regions.

A consensus has been reached around the notion that urban agglomerations will constitute the lifeblood of China's future economic development and urbanisation [3,42]. However, we need to raise awareness that accelerated economic growth and urbanisation might have resulted in enlarging economic gaps and in the inefficient utilisation of various resources in the urban agglomeration area. In the WUA region, great progress has been made in economic construction and social development since the implementation of the "Central Region Grow-Up Strategy" and the "1 +8 Wuhan Urban Agglomerations Development Strategy". However, the economic disparity in the WUA region expanded.

On the one hand, the economic disparity between the WUA region and the rest of the regions in Hubei Province widened. Since Hubei Province put forward the initiative to construct the " $1+8$ Wuhan city circle" in 2002, the provincial government has adopted a trickle-down growth strategy to inventively develop a few regional centres through measures such as providing more incentives and opportunities in support of the socio-economic transition of the WUA region. Consequently, the proportion of the financial support for the WUA region in terms of total financial investment greatly increased. Statistical data shows that the proportion of the WUA region's financial expenditure (FE) in relation to the province of Hubei rose from $38.9 \%$ in 2000 to $49.6 \%$ in 2010 ; the total investment in fixed assets (TIFA) correspondingly increased from $56.8 \%-62.6 \%$ (Figure 8 ). As a result, the proportion of the WUA region's GDP in relation to Hubei's increased from $58.4 \%-60.4 \%$.

Figure 8. The proportion of financial expenditure and investment in fixed assets of the WUA region in comparison to that of the province of Hubei.

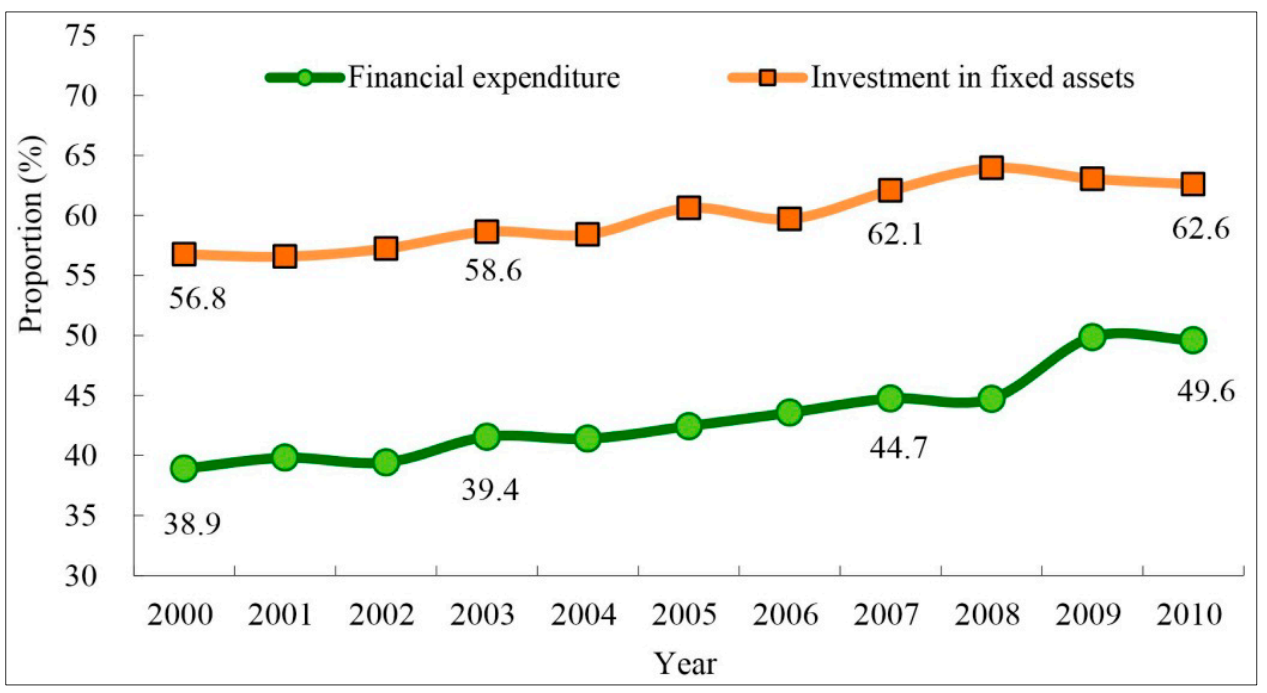

Source: Hubei Statistical Yearbook in 2011 [16]. 
On the other hand, economic disparity within the WUA region also increased. As the growth engine of the WUA region, as well as of central China, Wuhan took special advantage of its incomparable policy privileges, optimal location, and favourable socio-economic factors. However, Wuhan exerted a weak beneficial effect in diffusing capital, technology, personnel, and other factors to its neighbours, ultimately giving rise to poor urban-rural interactions and poor regional economic integration performance, which has contributed to the widened economic disparity within the WUA region. Statistical data shows that the proportion of Wuhan's GDP and financial revenue in relation to that of the WUA region has increased from $48.3 \%$ in 2000 to $57.8 \%$ in 2010, and from $58.7 \%-70.2 \%$ (Figure 9). The proportion of Wuhan's total population in proportion to the population of the WUA region has also sharply increased, rising from $24.8 \%$ in 1990 to $27.1 \%$ in 2000 and then to $32.4 \%$ in 2010 .

Figure 9. The proportion of Wuhan's gross domestic product and financial revenue in comparison to that of the WUA region.

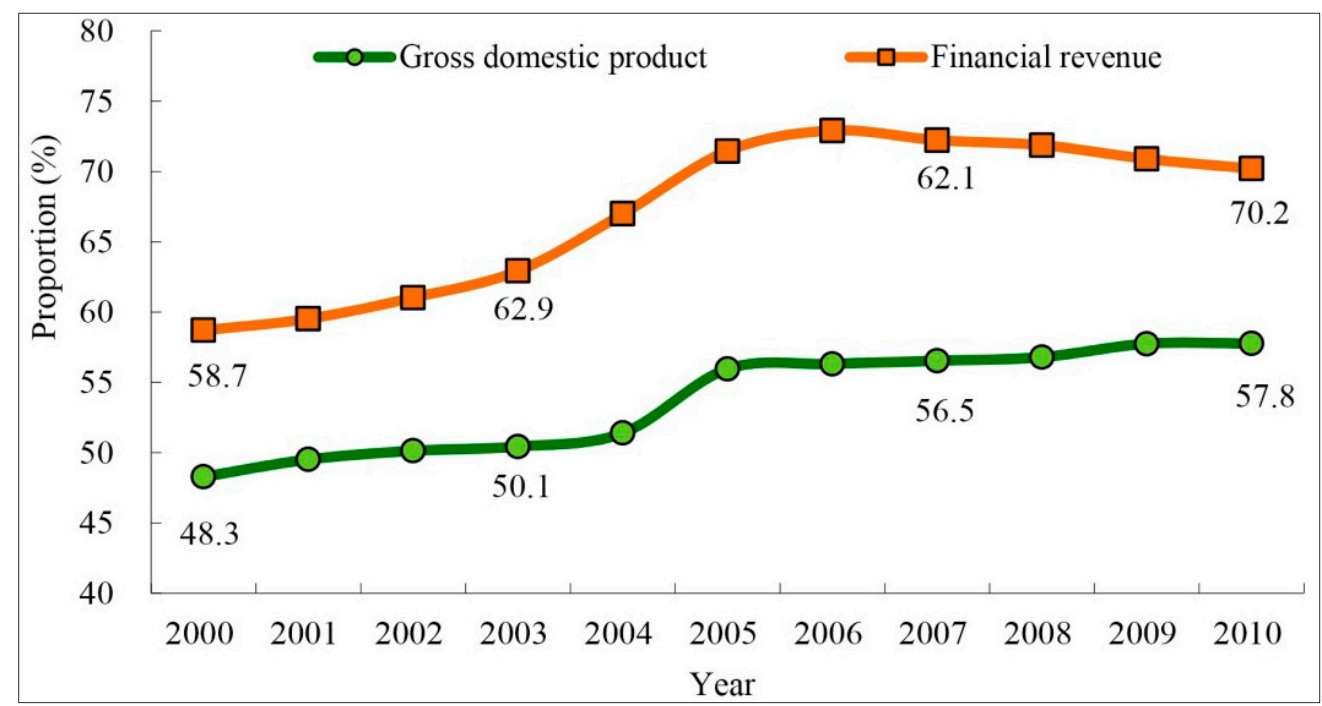

Source: Hubei Statistical Yearbook in 2011 [16].

Urban sprawl has been considered a common phenomenon in China's urbanisation process, especially in large cities. Urban sprawl in Wuhan leads to the inefficient utilisation of various resources, which is a serious problem that deserves attention [40]. For instance, the pace of urban land expansion in Wuhan was significantly faster than that of urban population growth. The average annual growth rate of the urban built-up area was $7.82 \%$, which is 4.7 times higher than that of the urban population (1.64\%) between 2001 and 2010. Traffic congestion in Wuhan has been exacerbated by urban sprawl. In order to fundamentally solve the problem, the municipal government has spent hundreds of millions of dollars to build $140 \mathrm{~km}$ of rail lines for rail transit, as well as the 11th Yangtze River Bridge. It can be seen that urban sprawl consumes not only large amounts of commuting time, but also leads to unnecessary economic losses, energy consumption, and environmental pollution.

In order to realize the sustainable development in the urban agglomeration area [43], the "Urban-Rural and Regional Integration Strategy" was designed and presented in order to avoid economic gaps and the inefficient utilisation of various resources. The strategy attaches emphasis to the outlet roads for rural-urban and regional development, not by making a blind rush for rapid urbanisation, but by seeking steady progress through the rural-urban equalized development [44]. Instead of farmland being 
lost to factory workshops and villages converted to cities, the rural-urban equalized development focuses on eliminating urban-rural differences in pursuit of the rural style of production and life by popularizing mechanical farming and creating a favorable rural living environment and employment condition in rural areas [45]. It highlights the socio-economic functions and value of rural China, promoting the inter- and intra-regional flow of production elements, cultivating self-innovative and specialized industries of township and villages, and elevating self-supporting capability, productivity and competitiveness of rural areas [46]. The core of the strategy is to manage the economic gap and avoid blind urban sprawl by concentrating industries within development zones, rural populations within townships, and land for scale operations within rural areas. In practice, those regions engaged in coordinating and balancing the development of cities of all sizes and strengthening the construction of small towns and central villages (communities) generally experienced more sustainable urbanisation and more harmonised urban-rural linkages [47]. Therefore, under China's current national conditions, there is an urgent need to scientifically arrange the urban system; plan small towns and pivotal villages (communities); and integrate urban-rural and regional organisations, industry, and space. We argue that promoting the equalised development of urban-rural and regional traffic and transport, economic investment, social services, ecological environment and quality of life, as well as enhancing the functioning of small towns and pivotal villages (communities) in terms of population convergence, industrial agglomeration, and spatial intensification, constitute strategic actions that will control the increasing economic disparity and blind urban sprawl currently evidenced in the WUA region.

\section{Conclusions}

Along with a series of privileged national development strategies and policies, the socioeconomic development and urban land expansion evidences a rapid transformation in the metropolitan areas located in central and western regions of China since the turn of the new millennium. The rapid economic growth in the metropolitan areas has resulted in the related socioeconomic transformations, drastic expansion of built-up areas, high-density concentration of population and industry, high-risk environmental damage as well as inefficient use of various resources. Taking Wuhan urban agglomeration as a case study, this paper has examined the spatio-temporal pattern of urban land expansion in the periods 1980-1990, 1990-2000, and 2000-2010 and the factors influencing this process, and presented a strategy to deal with the enlarging economic gaps and the inefficient utilisation of various resources. Various research methods employed in our study include Remote Sensing, GIS, and mathematical models.

The results indicate that WUA region experienced a rapid process of urban land expansion: between 1980 and 2010, the total area of urban land increased by 5.7 times, from $203.66-1370.07 \mathrm{~km}^{2}$. The urban expansion intensity presented significant stage and fluctuation characteristics between the different periods studied-the increase in urban land area in the three decades was $423.82 \mathrm{~km}^{2}$, $167.42 \mathrm{~km}^{2}$, and $574.93 \mathrm{~km}^{2}$, respectively. Geographically, the spatial expansion pattern of urban land was characterised by conspicuous concentration and regional imbalances during the study period. In the first decade, the urban expansion intensity of the central cities was significantly lower than that of the surrounding small and medium-sized cities/counties. In the second decade, urban land expansion in the east-west direction was replaced by expansion in a north-south direction, which became a new 
active zone. During the third decade, land use expansion formed a conspicuous concentration distribution pattern. The global fractal correlation dimension (GFCD) and the scaling behaviour indicate that the morphology of urban land varied among the four years studied -i.e., the spatial distribution of urban land in the study area shifted from a homogeneous pattern to a heterogeneous and concentrated pattern.

Industrialisation, urban population growth, land-use policies, urbanisation guidelines (governmental plans and regulations about urbanisation) and national development strategy are major factors that have contributed to spatio-temporal differences in urban expansion in the WUA region. However, it is worth noting that the dominant driving mechanism varied between different decades studied. Finally, an urban-rural and regional integration strategy was designed and presented. The strategy attaches emphasis to the outlet roads for rural-urban and regional development, not by making a blind rush for rapid urbanisation, but by seeking steady progress through the rural-urban equalized development, which might avoid economic gaps and blind urban sprawl in the urban agglomeration areas.

This study is an attempt for understanding the spatio-temporal patterns and policy implications of urban land expansion in metropolitan areas, as such, a number of research gaps still exist. For example, considering that the spatio-temporal patterns of urban land expansion are significantly different between the eastern region and central and western regions, it is necessary to explore deeply what make the differences between these regions. Besides, it is desired to introduce some advanced approaches, such as tentative geographically and temporally weighted regression (GTWR), hierarchical regression and panel regression to quantitatively analyse the factors and dynamic mechanisms of urban land spatial expansion, based on remote sensing data and socio-economic data.

\section{Acknowledgments}

The authors are indebted to the Major Program of the National Natural Science Foundation of China (Grant No. 11\&ZD042), the Excellent Team Construction Foundation of Beijing City (Grant No. 2008-411-30), and the Science and Technology Project of Ministry of Housing and Urban-Rural Development of China (Grant No. 2013-R2-25).

\section{Author Contributions}

Shasha $\mathrm{Lu}$ contributed to the development of the idea and participated in all phases. Xingliang Guan wrote the manuscript. Chao He helped perform the analysis with constructive discussions. Jiali Zhang helped improve the figures and manuscript. All authors have read and approved the final manuscript.

\section{Conflicts of Interest}

The authors declare no conflict of interest.

\section{References}

1. Ma, L.J.C. Urban transformation in China, 1949-2000: A review and research agenda. Environ. Plan. 2002, 34, 1545-1569. 
2. Long, H.L.; Zou, J.; Pykett, J.; Li, Y.R. Analysis of rural transformation development in China since the turn of the new millennium. Appl. Geogr. 2011, 31, 1094-1105.

3. Fang, C.L.; Guan, X.L.; Lu, S.S.; Zhou, M.; Deng, Y. Input-output efficiency of urban agglomerations in China: An application of data envelopment analysis (DEA). Urban Stud. 2013, 50, 2766-2790.

4. Xu, Z.L.; Zhu, N. City size distribution in China: Are large cities dominant? Urban Stud. 2009, $46,2159-2185$.

5. Chen, S.; Zeng, S.; Xie, C. Remote Sensing and GIS for urban growth analysis in China. Photogramm. Eng. Remote Sens. 2000, 66, 593-598.

6. Deng, X.Z.; Huang, J.K.; Rozelle, S.; Uchida, E. Economic growth and the expansion of urban land in China. Urban Stud. 2010, 47, 813-843.

7. National Bureau of Statistics of China (NBSC). China Statistical Yearbook; State Statistical Press: Beijing, China, 1982-2011.

8. Shao, M.; Tang, X.Y.; Zhang, Y.H.; Li, W.J. City clusters in China: Air and surface water pollution. Front. Ecol. Environ. 2006, 4, 353-361.

9. Jiang, F.; Liu, S.H.; Yuan, H.; Zhang, Q. Measuring urban sprawl in Beijing with geo-spatial indices. J. Geogr. Sci. 2007, 10, 469-478.

10. Gong, J.Z.; Liu, Y.S.; Xia, B.C. Spatial heterogeneity of urban land-cover landscape in Guangzhou from 1990 to 2005. J. Geogr. Sci. 2009, 19, 213-224.

11. Xie, Y.C.; Yu, M.; Tian, G.J.; Xing, X.R. Socio-economic driving forces of arable land conversion: A case study of Wuxian City, China. Global Environ. Chang. 2005, 15, 238-252.

12. Long, H.L.; Tang, G.; Li, X.B.; Heilig, G.K. Socio-economic driving forces of land-use change in Kunshan, the Yangtze River Delta economic area of China. J. Environ. Manag. 2007, 83, 351-364.

13. Kaufmann, R.K.; Seto, K.C. Change detection, accuracy, and bias in a sequential analysis of Landsat imagery in the Pearl River Delta, China: Econometric techniques. Agric. Ecosyst. Environ. 2001, 85, 95-105.

14. Tan, M.H.; Li, X.B.; Xie, H.; Lu, C.H. Urban land expansion and arable land loss in China-A case study of Beijing-Tianjin-Hebei region. Land Use Policy 2005, 22, 187-196.

15. Ma, R.H.; Gu, C.L.; Pu, Y.X.; Ma, X.D. Mining the urban sprawl pattern: A case study on Sunan, China. Sensors 2008, 8, 6371-6395.

16. Hubei Statistical Bureau (HSB). Hubei Statistical Yearbook; China Statistics Press: Beijing, China, 1981-2011.

17. Manandhar, R.; Odeh, I.O.; Ancev, T. Improving the accuracy of land use and land cover classification of landsat data using post-classification enhancement. Remote Sens. 2009, 1, 330-344.

18. Martínez, S.; Mollicone, D. From land cover to land use: A methodology to assess land use from remote sensing data. Remote Sensing 2012, 4, 1024-1045.

19. Liu, J.Y.; Liu, M.L.; Deng, X.Z.; Zhuang, D.F.; Zhang, Z.X.; Luo, D. The land use and land cover change database and its relative studies in China. J. Geogr. Sci. 2002, 12, 275-282.

20. Tian, G.; Liu, J.; Xie, Y.; Yang, Z.; Zhuang, D.; Niu, Z. Analysis of spatio-temporal dynamic pattern and driving forces of urban land in China in 1990s using TM images and GIS. Cities 2005, $22,400-410$. 
21. Wang, J.; Liu, Y.; Liu, Z. Spatio-temporal patterns of cropland conversion in response to the "Grain for Green Project" in China's Loess Hilly region of Yanchuan county. Remote Sens. 2013, $5,5642-5661$.

22. Liu, S.H.; Sylvia, P. Spatial Patterns and Dynamic Mechanisms of Urban Land Use Growth in China: Case Studies in Beijing and Shanghai; Interim Report IR-02-005; International Institute for Applied Systems Analysis: Laxenburg, Austria, 2002.

23. Tannier, C.; Pumain, D. Fractals in urban geography: A general outline and an empirical example. CyberGeo: Eur. J. Geogr. 2005, 307, 22-40.

24. Zhu, H.; Li, X. Discussion on the Index Method of Regional Land Use Change. Acta Geogr. Sin. 2003, 5, 643-650.

25. Guan, X.L.; Fang, C.L.; Zhou, M.; Wu, H. Spatio-temporal characteristics of spatial expansion of urban land in Wuhan urban agglomeration. J. Nat. Resour. 2012, 27, 1447-1459. (In Chinese)

26. Long, H.L.; Zou, J.; Liu, Y.S. Differentiation of rural development driven by industrialisation and urbanisation in eastern coastal China. Habitat Int. 2009, 33, 454-462.

27. Deng, X.Z.; Huang, J.K.; Rozelle, S.; Uchida, E. Growth, population and industrialisation, and urban land expansion of China. J. Urban Econ. 2008, 63, 96-115.

28. Wu, L.X.; Sun, B.; Zhou, S.L.; Huang, S.E.; Zhao, Q.G. A new fusion technique of remote sensing images for land use/cover. Pedosphere 2004, 14, 187-194.

29. Fang, C.L.; Lin, X.Q. The spatial integration and industrial rationalization organization of Wuhan Urban Agglomeration. Geogr. Res. 2008, 27, 397-408.

30. Pacione, M. The internal structure of cities in the third world. Geography 2001, 86, 189-209.

31. Zhu, L.; Jiang, Z. From brigade to village community: The land tenure system and rural development in China. Camb. J. Econ. 1993, 17, 441-461.

32. Yeh, A.G.O.; Li, X. Economic development and agricultural land loss in the Pearl River Delta, China. Habitat Int. 1999, 23, 373-390.

33. Liu, Y.S.; Fang, F.; Li, Y.H. Key issues of land use in China and implications for policy making. Land Use Policy 2014, 40, 6-12.

34. Lu, S.; Guan, X.; Zhou, M.; Wang, Y. Land resources allocation strategies in an urban area involving uncertainty: A case study of Suzhou, in the Yangtze River Delta of China. Environ. Manag. 2014, 53, 894-912.

35. Liang, Z.; White, M.J. Market Transition, Government Policies, and Interprovincial Migration in China: 1983-1988. Econ. Dev. Cult. Chang. 1997, 45, 321-339.

36. Zhao, S.X.B.; Chan, R.C.K.; Sit, K.T.O. Globalisation and the dominance of large cities in contemporary China. Cities 2003, 20, 265-278.

37. Fang, C.L.; Liu, X.L. Temporal and spatial differences and imbalance of China's urbanisation development during 1950-2006. J. Geogr. Sci. 2009, 19, 719-732.

38. Fan, C.C. Uneven development and beyond: Regional development theory in post-Mao China. Int. J. Urban Reg. Res. 1997, 21, 620-639.

39. Yang, D.L. Patterns of China's regional development strategy. China Q. 1990, 122, 230-257.

40. Yin, J.; Yin, Z.; Zhong, H.; Xu, S.; Hu, X.; Wang, J.; Wu, J. Monitoring urban expansion and land use/land cover changes of Shanghai metropolitan area during the transitional economy (1979-2009) in China. Environ. Monit. Assess. 2011, 177, 609-621. 
41. Sun, C.; Wu, Z.F.; Lv, Z.Q.; Yao, N.; Wei, J.B. Quantifying different types of urban growth and the change dynamic in Guangzhou using multi-temporal remote sensing data. Int. J. Appl. Earth Obs. Geoinf. 2013, 21, 409-417.

42. Zhang, T.W. Land market forces and government's role in sprawl: The case of China. Cities 2000, $17,123-135$.

43. Wong, S.W.; Tang, B.S. Challenges to the sustainability of "development zones": A case study of Guangzhou Development District, China. Cities 2005, 22, 303-316.

44. Gross, C.; Ritzinger, A.; Magel, H. Searching for the village of tomorrow Scenarios on the functionality of Bavarian villages in 2020. disP-Plan. Rev. 2011, 47, 44-55.

45. Stroessner, G. Land consolidation in Bavaria: Support given to rural areas. Irrig. Eng. Rural Plan. 1986, 9, 53-59.

46. Liu, Y.S.; Lu, S.S.; Chen, Y.F. Spatio-temporal change of urban-rural equalized development patterns in China and its driving factors. J. Rural Stud. 2013, 32, 320-330.

47. Song, S.; Zhang, K.H. Urbanisation and city size distribution in China. Urban Stud. 2002, 39, 2317-2327.

(C) 2014 by the authors; licensee MDPI, Basel, Switzerland. This article is an open access article distributed under the terms and conditions of the Creative Commons Attribution license (http://creativecommons.org/licenses/by/3.0/). 